\title{
HIV-HBV Coinfection among Individuals Attending the ICTC of a Tertiary Care Hospital in West Bengal, India
}

\author{
Jayeeta Sarkar, ${ }^{1}$ Bhaswati Bandyopadhyay, ${ }^{1}$ Runu Chakrabarty, ${ }^{2}$ Nemai Bhattacharya, ${ }^{1}$ \\ Srima Adhikari, ${ }^{1}$ Saiantani Mondal, ${ }^{1}$ Anurita Mukherjee, ${ }^{1}$ and Subhasish Kamal Guha ${ }^{1}$ \\ ${ }^{1}$ Calcutta School of Tropical Medicine, 108 Chittaranjan Avenue, Kolkata 700073, India \\ ${ }^{2}$ ICMR Virus Unit, Kolkata, ID \& BG Hospital Campus, GB4, 1st Floor, 57 Dr. Suresh Chandra Banerjee Road, Kolkata 700010, India
}

Correspondence should be addressed to Runu Chakrabarty; runugc@gmail.com

Received 27 May 2013; Accepted 16 July 2013

Academic Editors: S. Pöhlmann and V. Yedavalli

Copyright (C) 2013 Jayeeta Sarkar et al. This is an open access article distributed under the Creative Commons Attribution License, which permits unrestricted use, distribution, and reproduction in any medium, provided the original work is properly cited.

Background. Hepatitis B and HIV infections are serious global public health problems. Many of the countries with high HIV burden are also affected by high prevalence of hepatitis B infection, leading to frequent HIV/HBV coinfection. Seroprevalence study is important to assess the magnitude and dynamics of disease transmission and to decide the prevention and control strategy. There is limited data of seroprevalence of HIV/HBV co-infection in West-Bengal, India. Objective. To determine the seroprevalence of HBsAg (hepatitis B surface antigen) positivity among HIV infected individuals attending an integrated counselling and testing centre (ICTC) attached to a tertiary care hospital in eastern India. Materials and Methods. Serum samples collected over a period of 6 months from subjects attending the ICTC were screened for anti-HIV antibodies by using rapid card tests as per the National AIDS Control Organisation (NACO) protocol. Serum samples found to be reactive for HIV antibodies were tested for HBsAg by rapid card test. Results. The seroprevalence of anti-HIV antibody was 17.3\%. Among these samples $8.3 \%$ were positive for $\mathrm{HBsAg}$. Conclusion. A high prevalence of HIV/HBV co-infection among individuals attending the ICTC in this centre is a cause for concern and warrants urgent intervention.

\section{Introduction}

Hepatitis B virus (HBV) infection is prevalent throughout the world. Its prevalence is also high in India [1]. The modes of transmission of HBV and HIV are similar overtly by blood transfusion and covertly by percutaneous/permucosal routes. However the prevalence of HBV in the population varies according to the risk factors involved and the initial burden of infectious markers in the community. This may differ not only from country to country but also in different regions of the same country. Serum hepatitis B surface antigen (HBsAg) is a reliable marker of overt hepatitis B virus (HBV) infection [2]. In serum it is the first seromarker to indicate active HBV infection, either acute or chronic [2]. HBsAg serum levels result from a balance between virus biology and a host's immune system as well as the indirect expression of transcriptionally active covalently closed circular DNA (cccDNA) rather than the product of the viral replication [3]. Worldwide over 2 billion people are infected with HBV and more than
350-400 million have chronic HBV infection [4]. India has been placed into the intermediate zone of prevalence of hepatitis B (2-7\% prevalence rates) by WHO [5]. This infection is a leading cause of morbidity and mortality, not only because of the acute illness but also due to its chronic sequelae like chronic hepatitis, cirrhosis, and hepatocellular carcinoma, accounting for more than a million deaths worldwide $[6,7]$. In India, the estimated number of HIV/AIDS cases in 2011 was 2,088,642 and overall adult prevalence was 0.27 percent [8]. In 2011, China and India accounted for 37 percent of the world population [9]. It is estimated that India had approximately 1.16 lakh new adult HIV infections in 2011 against 2.7 lakh in 2000. HIV epidemic in India is concentrated in nature. The HIV prevalence among the high risk groups, that is, female sex workers, injecting drug users, men who have sex with men, and transgender, is about 20 times higher than the general population. Based on the report of HIV Sentinel Surveillance 2011, India has an estimated 14,500 new infections among children less than 12 years of age [8]. 
The data on hepatitis B coinfection among HIV infected patients is scarce in eastern India. The present study was designed to find the rate of HBsAg seropositivity among HIV infected patients, as studies have shown that HIV/HBV coinfection is known to result in higher viral load of hepatitis virus and greater liver damage [10].

\section{Materials and Methods}

2.1. Settings. The study was carried out in a tertiary care hospital during the period 30 January-31 July, 2012. HIV antibody detection was performed after the mandatory pretest counselling with informed consent of the client. Reactive results for HIV antibody testing were disclosed only after posttest counselling. Prior to CD4 enumeration and starting of antiretroviral therapy (ART), certain routine investigations are conducted on these patients. Among these investigations, screening for hepatitis B surface antigen positivity is an important prerequisite. Hence ethical considerations are not applicable.

2.2. Specimen. Five millilitres of venous blood sample was collected from all patients who came with laboratory requisitions for the testing of HIV antibodies. The blood was allowed to clot for 45 minutes at room temperature and the serum was separated after centrifugation at a low speed.

2.3. Serology. The serum collected was tested for HIV antibodies using standard recommended procedure. Briefly, rapid card tests were used in an algorithm of parallel testing. Kits that were used sequentially were SD Bioline for HIV 1/2 3.0 (Standard Diagnostics Inc., India). Samples that were reactive by this method were rechecked by two other rapid tests-HIV Triline Rapid HIV 1/2 (Bhat Bio-Tech India Pvt. Ltd.) and HIV Trispot Rapid HIV 1 and 2 (Bhat Bio-Tech India Pvt. Ltd).

HBsAg was determined by a rapid card test Hepacard (Biomed Industries, India). All the tests were performed in accordance with the manufacturer's instructions with adequate controls.

\section{Results}

A total of 2495 samples were tested for HIV antibody out of which $432(17.31 \%)$ were reactive. Among the HIV reactive cases, $36(8.33 \%)$ cases were also found to be reactive for HBsAg. Demographic data of the HIV infected patients included in this study is shown in Table 1. HIV-1 antibody was the prevalent type.

\section{Discussion}

The prevalence of hepatitis B virus infection varies from country to country and depends upon a complex mix of behavioural, environmental, and host factors. In general, it is lowest in countries or areas with high standards of living (e.g., Australia, North America, and North Europe) and highest in
TABLE 1: Distribution of age, gender, and high risk behaviour among individuals attending ICTC clinic.

\begin{tabular}{lcc}
\hline Groups & $\begin{array}{c}\text { HIV Positives } \\
(n=432)\end{array}$ & $\begin{array}{c}\text { HIV/HBV } \\
\text { Co-infection } \\
(n=36)\end{array}$ \\
\hline Age (years) & $6(1.4 \%)$ & $0(0 \%)$ \\
$<5$ & $11(2.5 \%)$ & $0(0 \%)$ \\
$5-14$ & $45(10.4 \%)$ & $2(5.6 \%)$ \\
$15-20$ & $88(20.3 \%)$ & $11(30.5 \%)$ \\
$21-30$ & $212(49 \%)$ & $21(58.3 \%)$ \\
$31-45$ & $70(16.2 \%)$ & $2(5.6 \%)$ \\
$>45$ & & \\
Gender & $287(66.4 \%)$ & $30(83.3 \%)$ \\
Male & $145(33.6 \%)$ & $6(16.7 \%)$ \\
Female & & \\
High risk behaviour & $327(74.7 \%)$ & $25(69.4 \%)$ \\
Heterosexual & $16(3.7 \%)$ & $2(5.6 \%)$ \\
Men having sex with men & $6(1.4 \%)$ & $1(2.8 \%)$ \\
Sex worker & $17(3.9 \%)$ & $1(2.8 \%)$ \\
Injecting drug user & $21(4.9 \%)$ & $1(2.8 \%)$ \\
Blood transfusion & $21(4.9 \%)$ & $0(0 \%)$ \\
Mother to child & $24(5.5 \%)$ & $6(16.7 \%)$ \\
Unknown & &
\end{tabular}

countries or areas with low socioeconomic status (e.g., China, Southeast Asia, South America, and Africa) [11].

Studies have shown that the prevalence of hepatitis B coinfection with HIV increases with progression in clinical staging of HIV [12]. For instance, the prevalence of hepatitis $\mathrm{B}$ infection in WHO stage 3 was $17 \%$, and in stage 4 , it was $83 \%$ [13]. A similar pattern of incidence of HIV/HBV coinfection with disease progression was observed in a study in India [14]. In the present study seroprevalence of hepatitis B surface antigen positivity within HIV-infected individuals was noted to be $8.3 \%$. High prevalence could have a bearing on the disease outcome among this population. HIV/HBV coinfection has also been reported in other studies. Anwar et al. reported a prevalence of $6.3 \%$ in Lahore [12], whereas Uneke et al. and Mendes-Corrêa et al. reported 25.9\% and $5.7 \%$, respectively $[15,16]$. However there are no follow-up studies to show the outcome of this coinfection.

Age and gender variations have been noted in several studies across India. A hospital-based study conducted in Hyderabad (Andhra Pradesh) showed that 4.3\% males and $2 \%$ females were positive for HIV antibodies in the general populations and the highest prevalence belonged to age group 21-30 years [17]. In contrast the present study showed the highest prevalence in the age group of 31-40 years. In all epidemiological studies, the age of acquiring infection is the major determinant of the incidence and prevalence rates. In this survey, the difference in prevalence of HIV and $\mathrm{HIV} / \mathrm{HBV}$ coinfection in various age groups indicates that, this factor plays an important role in the prevalence rates. 
The age groups of $15-45$ years showed the highest prevalence for $\mathrm{HIV} / \mathrm{HBV}$ and $\mathrm{HIV}$, respectively, in the present study.

The seroprevalence of HIV infection among males and females in our study was $66.4 \%$ and $33.6 \%$, respectively. $83.3 \%$ of the HIV infected males and $16.7 \%$ of the female patients were positive for HBsAg. These figures are different from the report of a hospital-based study in Nigeria. Adewole et al. observed positive HBsAg in 50\% males and females among HIV infected population each [13].

This is the first report of HIV/HBV coinfection among the population visiting an integrated testing and counseling centre attached to a tertiary care hospital in Kolkata, West Bengal. The observed rates reflect the patient population served by our hospital and do not necessarily apply to other centres. We have shown that HIV/HBV coinfection occurs in our environment at rates that are comparable with those of other reports. Shared transmission pathways and synergistic effects of both viruses have an impact on morbidity and mortality of HIV. Screening for HBV should be included in the armamentarium of investigations to be done pre-HAART. This study throws some light on the dynamics of viral transmission in this part of the country. The estimation of the seroprevalence of HIV/HBV coinfection provides reference for future studies on disease progression and also essential information for effective implementation of control program.

\section{Conflict of Interests}

All the authors have no financial conflict of interests.

\section{Acknowledgments}

The study was funded by Indian Council of Medical Research (ICMR), India (IRIS ID NO. 2009-05630). The authors specially extend our gratitude to the staff of our Department and all participants of this study.

\section{References}

[1] A. Batham, D. Narula, T. Toteja, V. Sreenivas, and J. M. Puliyel, "Systematic review and meta-analysis of prevalence of hepatitis B in India," Indian Pediatrics, vol. 44, no. 9, pp. 663-674, 2007.

[2] D. N. Bukbuk, A. P. Bassi, and Z. M. Mangoro, "Sero-prevalence of hepatitis B surface antigen among primary school pupils in rural Hawal valley, Borno State, Nigeria," Journal of Community Medicine and Primary Health Care, vol. 17, no. 1, pp. 20-23, 2005.

[3] M. R. Brunetto, "A new role for an old marker, HBsAg," Journal of Hepatology, vol. 52, no. 4, pp. 475-477, 2010.

[4] D. Lavanchy, "Hepatitis B virus epidemiology, disease burden, treatment, arid current and emerging prevention and control measures," Journal of Viral Hepatitis, vol. 11, no. 2, pp. 97-107, 2004.

[5] S. Qamer, T. Shahab, S. Alam, A. Malik, and K. Afzal, "Agespecific prevalence of hepatitis B surface antigen in pediatric population of Aligarh, North India," Indian Journal of Pediatrics, vol. 71, no. 11, pp. 965-967, 2004.

[6] R. H. Purcell, “The discovery of the hepatitis viruses," Gastroenterology, vol. 104, no. 4, pp. 955-963, 1993.
[7] W. M. Lee, "Review article: hepatitis B virus injection," The New England Journal of Medicine, vol. 337, no. 24, pp. 1733-1745, 1997.

[8] National AIDS Control Organization, "HIV Sentinel Surveillance 2010-11: A Technical Brief,” December 2012.

[9] "World Population Prospects, the 2010 Revision volume I: Comprehensive Tables," United Nations, New York, NY, USA, 2011.

[10] S. B. Sonth, M. S. Sathyanarayan, J. Mariraj, and S. Krishna, "Seroprevalence of HIV-HBV co-infection," Al Ameen Journal of Medical Science, vol. 5, no. 2, pp. 183-186, 2012.

[11] S. Sood and S. Malvankar, "Seroprevalence of Hepatitis B surface antigen, antibodies to the Hepatitis $C$ virus, and human immunodeficiency virus in a hospital-based population in Jaipur, Rajasthan," Indian Journal of Community Medicine, vol. 35, no. 1, pp. 165-169, 2010.

[12] M. S. Anwar, M. Nafees, and U. Nabi, "Sero-prevalence of HCV and associated infections with HIV and HBV among prisoners in Lahore," Biomedica, vol. 27, pp. 119-122, 2011.

[13] O. O. Adewole, E. Anteyi, Z. Ajuwon et al., "Hepatitis B and $\mathrm{C}$ virus co-infection in Nigerian patients with HIV infection," Journal of Infection in Developing Countries, vol. 3, no. 5, pp. 369-375, 2009.

[14] S. Saravanan, V. Velu, N. Kumarasamy et al., "Coinfection of hepatitis B and hepatitis C virus in HIV-infected patients in south India," World Journal of Gastroenterology, vol. 13, no. 37, pp. 5015-5020, 2007.

[15] C. J. Uneke, O. Ogbu, P. U. Inyama, G. I. Anyanwu, M. O. Njoku, and J. H. Idoko, "Prevalence of hepatitis-B surface antigen among blood donors and human immunodeficiency virusinfected patients in Jos, Nigeria," Memorias do Instituto Oswaldo Cruz, vol. 100, no. 1, pp. 13-16, 2005.

[16] M. C. J. Mendes-Corrêa, A. A. Barone, N. D. P. Cavalheiro, F. M. Tengano, and C. Guastini, "Prevalence of hepatitis B and C in the sera of patients with HIV infection in São Paulo, Brazil," Revista do Instituto de Medicina Tropical de Sao Paulo, vol. 42, no. 2, pp. 81-85, 2000.

[17] M. U. Rasheed and K. Hemalatharao, "Seroprevalence of HIV in a hospital based population and blood bank donors in South India," Indian Journal of Medical Microbiology, vol. 22, no. 1, p. 66, 2004. 

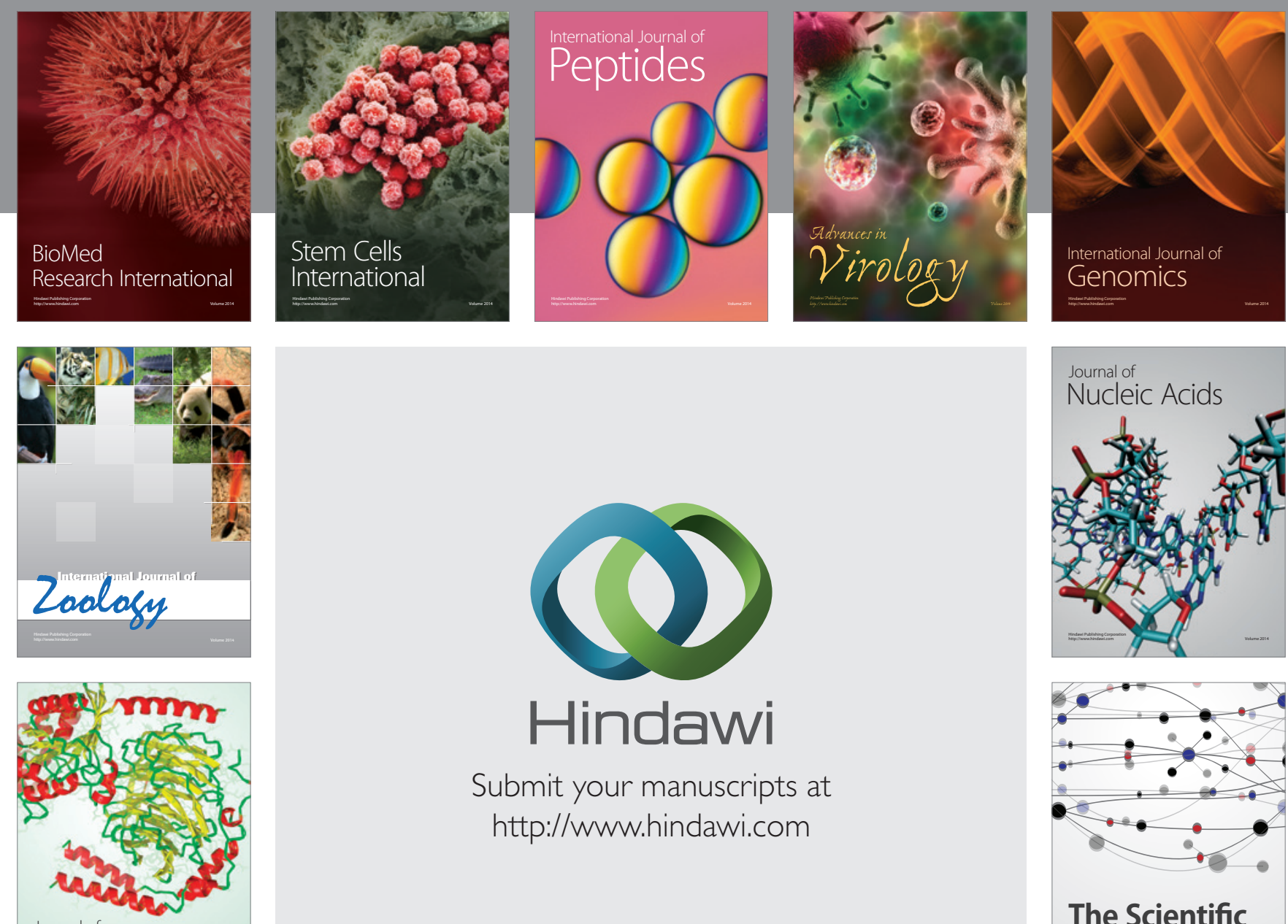

Submit your manuscripts at

http://www.hindawi.com

Journal of
Signal Transduction
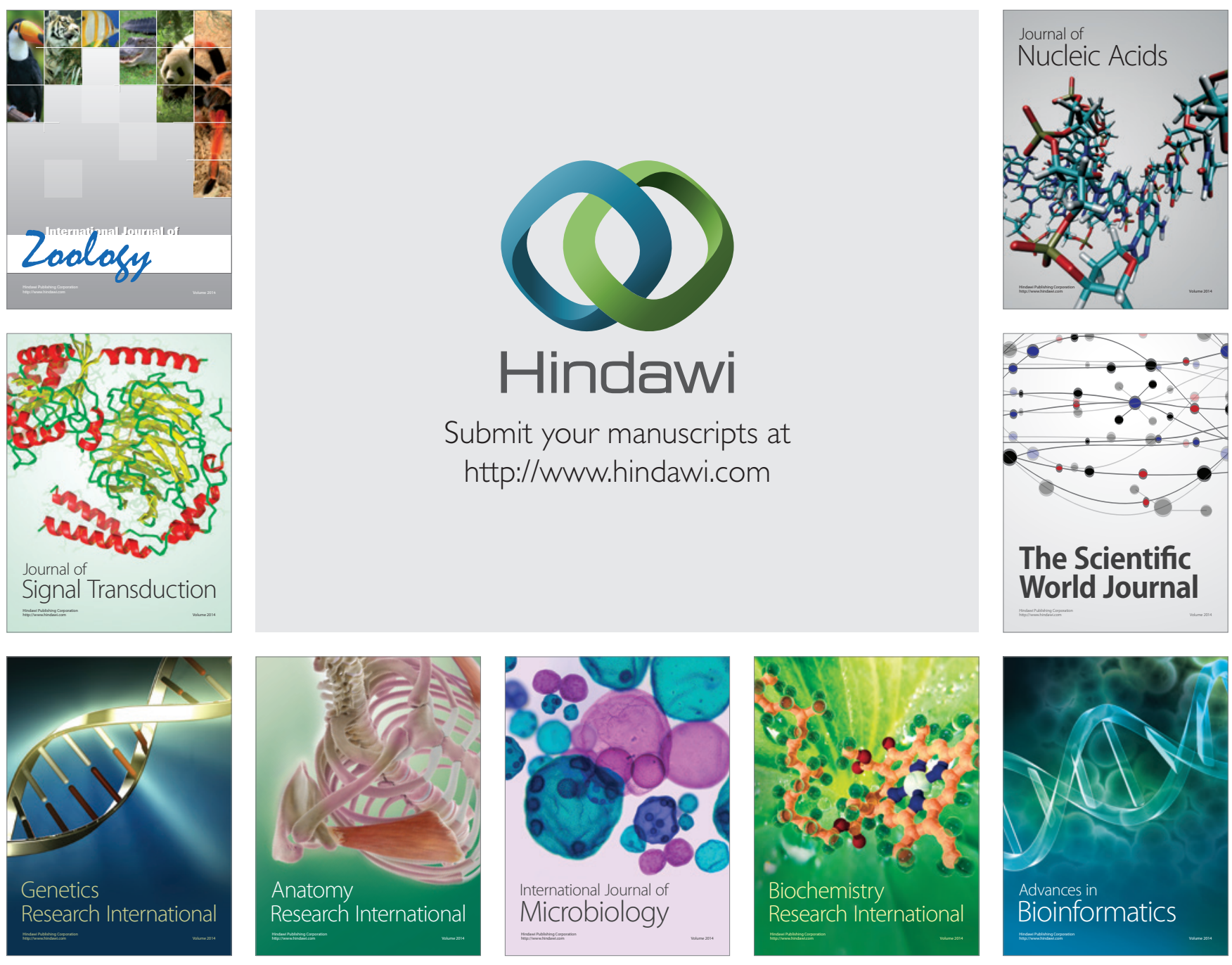

The Scientific World Journal
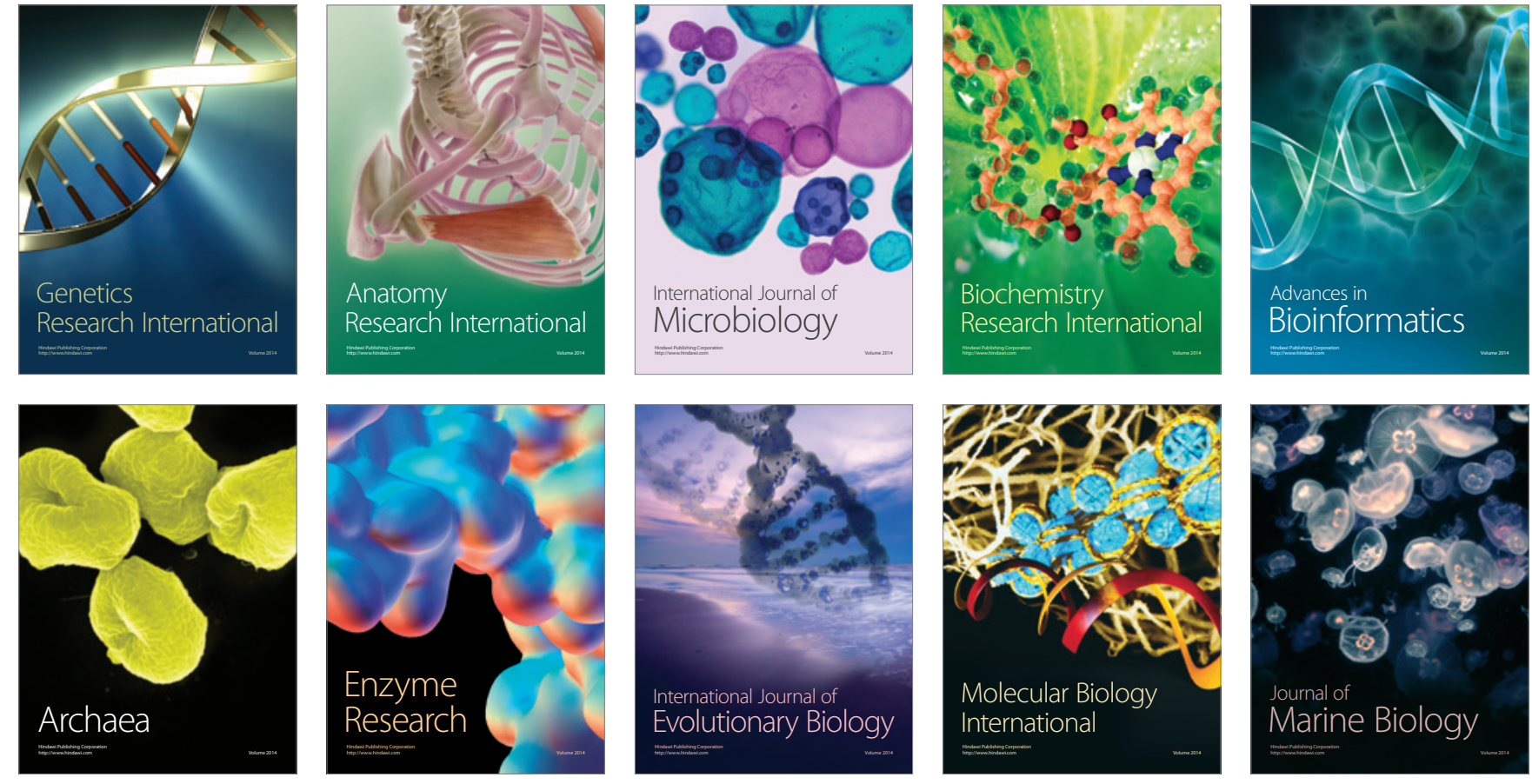